\title{
The Sensitivity of Total Ozone and Ozone Perturbation Scenarios in a Two-Dimensional Model Due to Dynamical Inputs
}

\author{
Charles H. JaCkMAN
}

NASA Godda'd Space Flight Center, Greenbelt, Maryland

Anne R. Douglass'

Applied Research Corporation, Landover, Maryland

Paul. D. Guthrie and Richard S. Stolarski

NASA Goddard Space Flight Center, Greenbelt, Maryland

\begin{abstract}
The sensitivity of the total ozone distributson in our two-dimensional photochemical model to dynamical inputs has been explored. The residual circulation has been computed from three sets of heating rates but using the same temperature distributions. These heating rates result in advection fields that are appropriately linked with the magnitude of their vertical winds in the lower stratosphere and are called: (1) the strong circulation, (2) the weak circulation, and (3) the combined circulation. Three different formulations of horizontal eddy diffusion have also been investigated, including (1) a small constant diffusion, (2) a computed diffusion from potential vorticity using measured temperatures, and (3) a self-consistent diffusion determıned from the meridional velocity. Finally, we studied two different formulations of vertical eddy diffusion: (1) a small constant diffusion and (2) an altitude-dependent larger diffusion. Our modeled global average total ozone varies by up to $10 \%$, depending on the varıous dynamical inputs, and the seasonal and latitudinal variabilities are even more substantial. The calculations indicate that total ozone in the middle to high latitudes is very sensitıve to the advection field below 100 mbar, the region where the heating rates (which are used in computing the advection field) are most uncertain. Modeled total ozone shows better agreement with solar backscattered ultraviolet (SBUV) ozone climatology, when computed horizontal eddy diffusion is used. Our "best" modeled total ozone distribution is a result of using the heating rates from Rosenfield et al. (1987) for pressures less than 100 mbar, along with heating rates from Dopplick $(1974,1979)$ for pressures greater than 100 mbar. Our model results, especially when comparing model and SBUV ozone between 10 and 1 mbar, indicate that there is an inconsistency between our "best" horizontal eddy diffusion and the "best" mean residual circulation. Our studies indicate a relative sımılarity of a typical ozone perturbation scenario among the different dynamical inputs. All of the perturbation studies predict the smallest ozone changes in the tropical latitudes, with larger ozone changes in the middle to high latitudes. The major changes in the various perturbation results are in the middle to high latıtudes: (J) the peak ozone change is off of the pole in the southern hemisphere (near $60^{\circ} \mathrm{S}$ latitude) using the strong circulation but centered on the pole for the varıous other dynamical studies, and (2) the maximum ozone change is centered at times varying from early spring to early summer, depending on which dynamical input is used.
\end{abstract}

\section{INTRODUCTION}

The prediction of present-day atmospheric ozone and the change in atmospheric ozone due to increases in trace gases (such as $\mathrm{CH}_{3} \mathrm{Cl}, \mathrm{CF}_{2} \mathrm{Cl}_{2}, \mathrm{CF}_{3} \mathrm{Cl}, \mathrm{CH}_{3} \mathrm{CCl}_{3}, \mathrm{CCl}_{4}, \mathrm{CH}_{4}, \mathrm{~N}_{2} \mathrm{O}$, and $\mathrm{CO}_{2}$ ) has been of concern to atmospheric scientists and policy makers for the past 15 years [Climatic Impact Assessment Program (CIAP) 1974; National Aeronautics and Space Administration (NASA), 1979; World Meteorological Organization (WMO), 1982, 1986]. One-, two-, and threedimensional photochemical atmospheric models have been used to predict the ozone distribution and the change in ozone that might be expected from increases in the other gases. In recent years, two-dimensional (2D) models have

'Now at University Space Research Associatıon, Columbıa, Maryland.

Copyright 1989 by the American Geophysical Union.

Paper number 89JD00459.

0148-0227/89/89JD-00459\$05.00 been the "workhorses" for assessing the influence of mankind on the stratosphere. A 2D zonal average model is less complex and less computer time consuming than a threedimensional (3D) model, but it can be used to predict the seasonal distributions of stratospheric gases to a reasonable accuracy (see, for example, WMO [1986]).

Total ozone and ozone change due to perturbation scenarios are probably the most important outputs of atmospheric 2D models. A variety of total ozone distributions have been computed from the several 2D models in use [WMO, 1986]. Each uncoupled 2D model has a formulation of photochemical and dynamical influences on atmospheric constituents, which is, in general, different from that used in other models; however, the ozone depletion predictions from the various models are similar. In particular, all uncoupled 2D ozone depletion predictions indicate that the largest ozone deple-

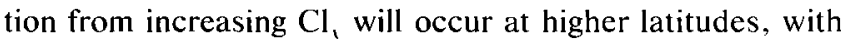
smaller ozone depletion at tropical latitudes.

A coupled 2D model study [Eckman et al., 1987] has recently indicated the possibility that more ozone depletion 
may occur at low, rather than high latitudes, if the ozone and carbon dioxide changes are coupled back into the dynamics of the model. Several other papers have indicated that dynamical changes can cause substantial changes in the distribution of total ozone (see, for example, Harwood and Pyle [1980]; Haigh and Pyle [1982]; Rood and Schoeberl [1983]; Haigh [1984]; and Solomon et al. [1985]).

Most of these earlier studies on dynamical influences on ozone have limited their work to the total ozone distribution. We use our full chemistry 2D model to investigate the effects of a range of reasonable dynamical inputs on ozone as well as ozone perturbation scenarios. We compare our model ozone results to solar backscattered ultraviolet (SBUV) ozone data because of the profile information available and, also, compare and contrast our modeled ozone and ozone perturbation results for the various dynamical inputs used.

This paper is divided into five sections. The model is described in section 2 . Six model experiments using separate dynamical inputs are investigated, discussed, and compared in section 3 . We compare perturbation results of these model experiments in section 4 . Finally, we discuss the results of our study and offer some conclusions in section 5 .

An appendix is included to show how some other species, besides ozone, vary with the different dynamical inputs. These other species include $\mathrm{N}_{2} \mathrm{O}, \mathrm{CH}_{4}$, and odd nitrogen $(\mathrm{N}$, $\mathrm{NO}, \mathrm{NO}_{2}, \mathrm{NO}_{3}, \mathrm{HNO}_{3}, \mathrm{HO}_{2} \mathrm{NO}_{2}, \mathrm{~N}_{2} \mathrm{O}_{5}$, and $\mathrm{ClONO}_{2}$ ), which is referred to as $\mathrm{NO}_{1}$.

\section{Model Description}

We use the 2D model described by Douglass et al. [this issue] in our analysis. This model covers the latitude range from $-85^{\circ}$ to $+85^{\circ}$ in $10^{\circ}$ latitude bands. The altitude range is from the ground up to $0.23 \mathrm{mbar}$ (about $60 \mathrm{~km}$ ) in a grid of log pressure with 30 pressure levels, which gives a spacing of about $2 \mathrm{~km}$ between grid boxes. A family approach is used in transporting the groups of species $\mathrm{O}_{1}\left(\mathrm{O}_{3}, \mathrm{O}\left({ }^{1} D\right)\right.$, and $\mathrm{O}\left({ }^{3} P\right)$ ), $\mathrm{NO}_{y}$, not including $\mathrm{HNO}_{3},\left(\mathrm{~N}, \mathrm{NO}, \mathrm{NO}_{2}, \mathrm{NO}_{3}, \mathrm{HO}_{2} \mathrm{NO}_{2}\right.$, $\mathrm{N}_{2} \mathrm{O}_{5}$, and $\left.\mathrm{ClONO}_{2}\right)$, and $\mathrm{Cl}_{1}(\mathrm{Cl}, \mathrm{ClO}, \mathrm{HOCl}, \mathrm{HCl}$, and $\mathrm{ClONO}_{2}$ ). Partitioning among the family members is done in the manner described by Douglass et al. [this issue]. Other transported species include $\mathrm{HNO}_{3}, \mathrm{~N}_{2} \mathrm{O}, \mathrm{CH}_{4}, \mathrm{H}_{2}, \mathrm{CO}$, $\mathrm{CH}_{3} \mathrm{OOH}, \mathrm{CFCl}_{3}, \mathrm{CF}_{2} \mathrm{Cl}_{2}, \mathrm{CH}_{3} \mathrm{Cl}, \mathrm{CCl}_{4}$, and $\mathrm{CH}_{3} \mathrm{CCl}_{3}$. The $\mathrm{HO}_{x}$ species $\mathrm{H}, \mathrm{OH}, \mathrm{HO}_{2}$, and $\mathrm{H}_{2} \mathrm{O}_{2}$ and the hydrocarbons $\mathrm{CH}_{3}, \mathrm{CH}_{3} \mathrm{O}, \mathrm{CH}_{3} \mathrm{O}_{2}, \mathrm{CH}_{2} \mathrm{O}$, and $\mathrm{CHO}$ are calculated using photochemical equilibrium assumptions. The $\mathrm{H}_{2} \mathrm{O}$ distribution is fixed and is taken from Limb Infrared Monitor of the Stratosphere (LIMS) measurements, along with previous 2D model computations for tropospheric values [see Jackman et al., 1987]. The boundary condition for ozone is assumed to be a deposition velocity of $0.1 \mathrm{~cm} \mathrm{~s}^{-1}$. Boundary conditions for the other various transported species are as given by Douglass et al. [this issue], with the exceptions of $\mathrm{HNO}_{3}$ (set to 90 parts per trillion by volume (pptv)) and $\mathrm{NO}_{v}$, not including $\mathrm{HNO}_{3}$, (set to $10 \mathrm{pptv}$ ).

The major species $\mathrm{N}_{2}\left(78 \%\right.$ of the atmosphere) and $\mathrm{O}_{2}$ ( $21 \%$ of the atmosphere) were computed using the temperature field from the National Meteorological Center (NMC) and from CIRA (1972) [Rosenfield et al., 1987] and by solving the hydrostatic equation. Reaction rates and photodissociation cross sections are taken from DeMore et al. [1987]. Model time steps are slightly more than 1 day (one time step $=$ one "long" day $=$ on day * (365/360)) and a model year is taken to be 360 of these "long" days.

\section{Model EXPERIMENTS}

In this section we discuss six model experiments in which the photochemical reaction rates are held constant and only the dynamics are changed. The three different circulations studied were (1) the strong circulation (designated case A), (2) the weak circulation (designated case B), and (3) the combined circulation (designated case $\mathrm{C}$ ). These nomenclatures arise from the magnitude of the vertical velocities in the lower to middle stratosphere. All three different circulation experiments had the same eddy diffusion representation, which is discussed in section 3.1.1. The three different eddy diffusion studies used the combined circulation and included (1) small horizontal eddy diffusion (designated case D), (2) self-consistently computed horizontal eddy diffusion (designated case E), and (3) large vertical eddy diffusion (designated case F). We compare and contrast the results of these model experiments in the following paragraphs.

\subsection{Influence of Circulation Changes on Total Ozone}

3.1.1. Strong circulation. For our first model experiment we use the residual circulation described by Jackman et al. [1987, 1988]. This circulation is computed using heating rates and temperatures from Rosenfield et al. [1987] for pressures less than $\mathbf{1 0 0}$ mbar. For pressures greater than 100 mbar, we use heating rates from Wei et al. [1983]. The temperatures are taken from the 4-year average (1979-1983) of NMC data for pressures greater than 0.4 mbar and from CIRA (1972) for pressures less than 0.4 mbar [Rosenfield et al., 1987]. The temperature distribution changes monthly and is the same in all model experiments included in this study. The resultant advection field is what we call the "strong circulation." The streamlines of the circulation for the months March, June, September, and December are given in Figure 1. There is strong upwelling in the tropical latitudes, and the motion is down at all times of the year for pressures greater than 100 mbar at the polar latitudes. The stratosphere shows the typical residual circulation pattern, with mostly upward motion above 10 mbar in the summer hemisphere middle to high latitudes, meridional motion from the summer hemisphere toward the winter hemisphere (especially at the low latitudes), and downward motion in the winter hemisphere.

The eddy diffusion is computed from the same data set used to derive the residual circulation. The $K_{v v}$, which are from Newman et al. [1988], were derived from a potential vorticity computation using NMC temperatures. The $K_{y z}$ simply represent the ratio of the mixing on isentropic surfaces to the mixing on pressure surfaces and are computed from the $K_{v v}$ values and the potential temperature [Newman et al., 1988; Jackman et al., 1988]. The vertical eddy diffusion $K_{z T}$ is assumed to be small in the stratosphere $(2 \times$ $\left.10^{3} \mathrm{~cm}^{2} \mathrm{~s}^{-i}\right)$, increasing with decreasing altitude from the tropopause to $1 \times 10^{5} \mathrm{~cm}^{2} \mathrm{~s}^{-1}$ at the ground.

In order to compare our model computations with ozone data, we chose a 3-year average (1979-1981) of SBUV measurements (Richard McPeters, private communication, 1988) which are a few percent different from those given by McPeters et al. [1984]. These new data were derived using the recently measured ozone cross sections given by Bass and Paur [1985] and Paur and Bass [1985]. These total ozone SBUV measurements are given in Figure 2. As is done in the 

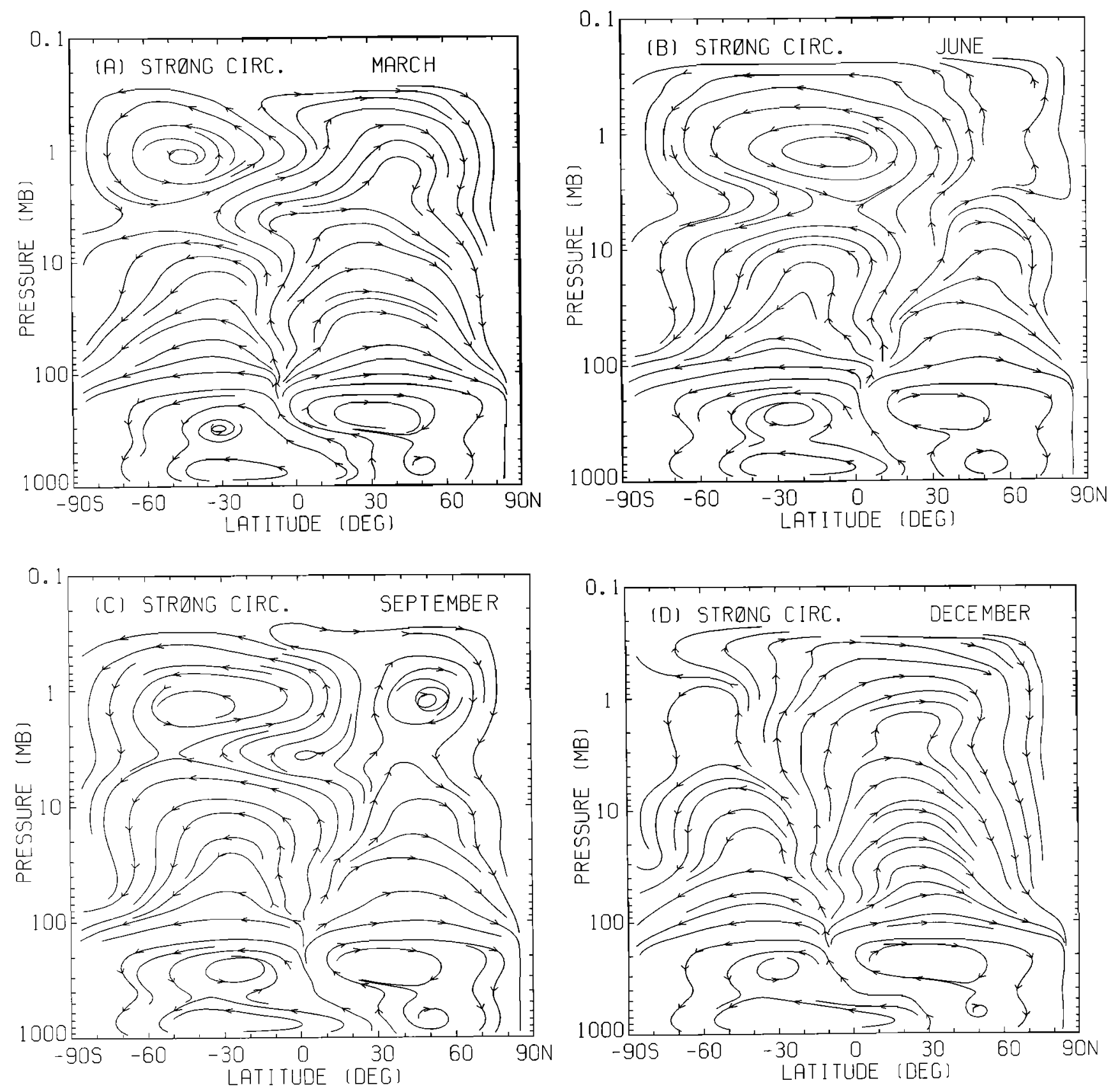

Fig. 1. Streamlines of the "strong circulation", case A. for four separate months: (a) March, (b) June, (c) September, and $(d)$ December.

model, we condense the 365-day year for SBUV data to 360 days for easier model-to-data comparison.

The "strong circulation," as well as all other model computations discussed in this paper, was run for 20 model years, enough time for all transients to disappear. The total ozone from this "strong circulation" is given in Figure 3.

Note the differences between Figures 2 and 3. Tropical ozone values of less than 240 to 260 Dobson units (DU) are apparent from the model computation, whereas measured tropical ozone is less than 260-280 DU. At winter high northern latitudes the SBUV data show values greater than $440 \mathrm{DU}$, while the model indicates values in excess of 800 DU. The data and model are even more different in the southern hemisphere. The data show a maximum off the pole, with a value over $380 \mathrm{DU}$, while the model indicates a maximum on the pole, with a value larger than $600 \mathrm{DU}$.

We have derived a yearly global average total ozone amount, $T_{\mathrm{O}_{2}}$, which we compute from the following relationship

$$
T_{\mathrm{O}_{3}}=\frac{\int_{0}^{360 \text { days }} \int_{-90^{\circ}}^{+90^{\circ}} \sigma_{\mathrm{O}_{3}}(t, \theta) \cos \theta d \theta d t}{\int_{0}^{360 \text { days }} \int_{-90^{\circ}}^{+90^{\circ}} \cos \theta d \theta d t} \mathrm{DU}
$$

where $\sigma_{\mathrm{O}_{3}}(\theta, t)$ is the total ozone at a latitude $\theta$ and time $t$. The model computation (designated case A) shows a $T_{\mathrm{O}_{3}}$ of 


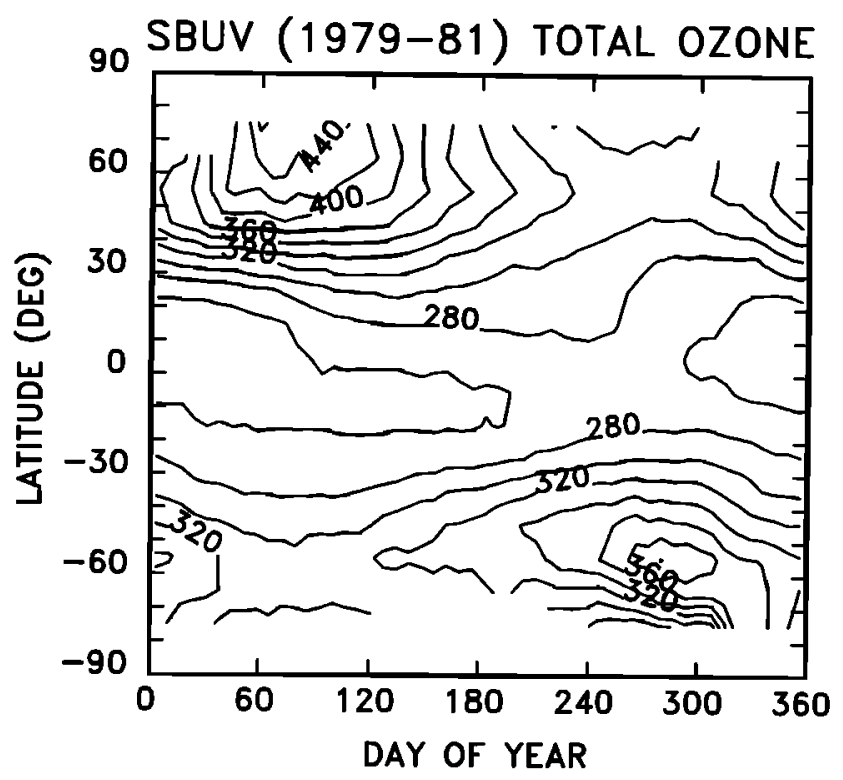

Fig. 2. Total ozone (in Dobson units) from a 3-year average SBUV (1979-1981) data set; contours represented are 260, 280, 300, $320,340,360,380,400,420,440$, and $460 \mathrm{DU}$.

$290 \mathrm{DU}$, whereas the data show a $T_{\mathrm{O}_{3}}$ of $298 \mathrm{DU}$. Case $\mathrm{A} T_{\mathrm{O}_{3}}$ is $\sim 3 \%$ smaller than the data and the modeled ozone distribution from case $A$ is incorrectly distributed when compared to data.

The SBUV data also have profile information. To use this more detailed information in the analysis of the model computations, we divided the total ozone into three altitude bands: surface ( 1000 mbar) to $100 \mathrm{mbar}, 100-10 \mathrm{mbar}$, and 10-1 mbar. The SBUV data are given in Figure 4 in terms of Dobson units for each of the bands. Further details on the SBUV data and the corresponding uncertainties as a function of altitude are given by McPeters et al. [1984]. The SBUV ozone data in the altitude band from the surface to 100 mbar are based on the measurement of total ozone by

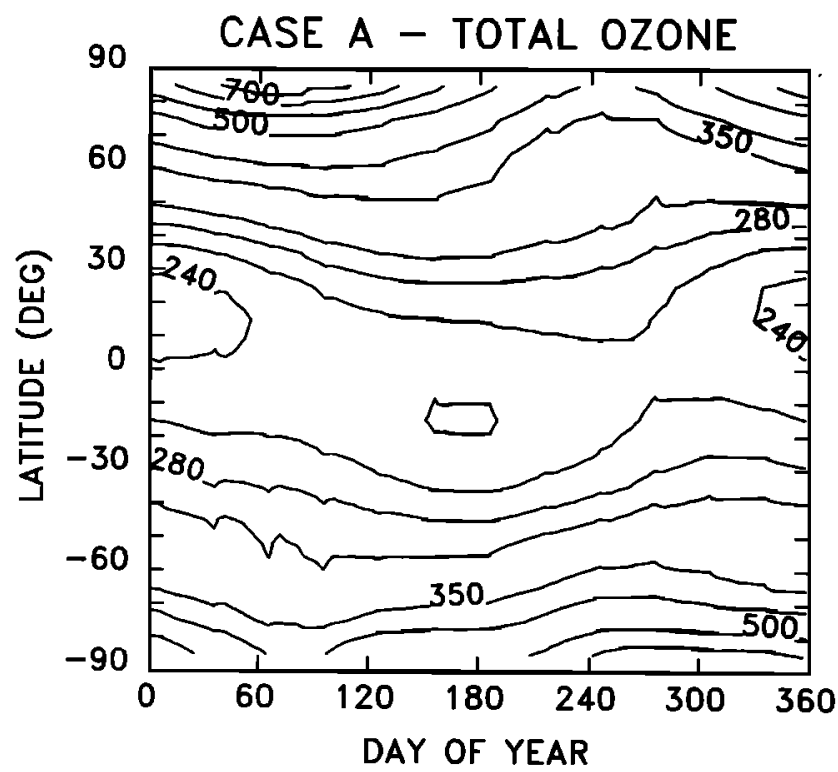

Fig. 3. Total ozone (in Dobson units) from model case A (strong circulation); contours represented are $240,260,280,300,350,400$. $500,600,700$, and $800 \mathrm{DU}$.
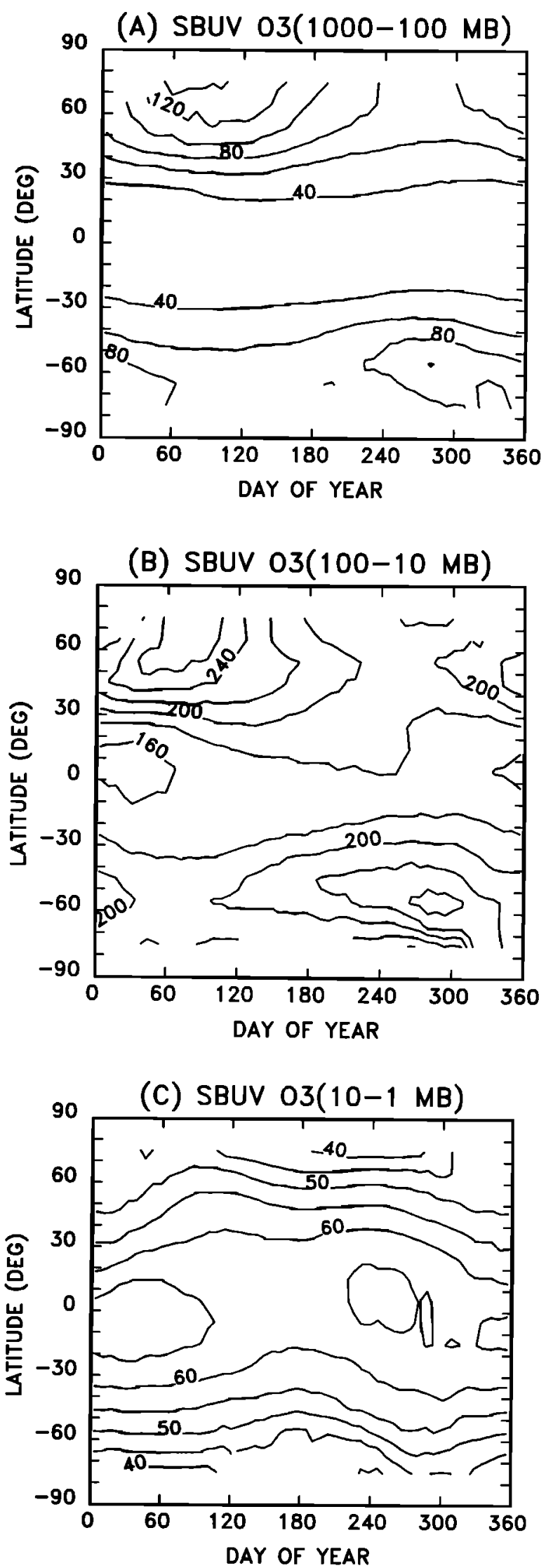

Fig. 4. Total ozone (in Dobson units) in three layers from SBUV data: (a) surface up to 100 mbar (contours represented are 40 , $60,80,100,120$, and $140 \mathrm{DU}$ ); (b) 100-10 mbar (contours represented are 160, 180, 200, 220, 240, and 260 DU); and (c) 10-1 mbar (contours represented are $40,45,50,55,60$, and $65 \mathrm{DU}$ ). 
SBUV and ozone climatology; uncertainties reach $32 \%$ in this band. The SBUV ozone data for pressures less than 100 mbar have uncertainties varying from 3 to $18 \%$, depending on the pressure.

We present similar plots for the case $A$ ozone results in Figure 5. There are more similarities between the modeled and observed ozone in the bands 100-10 mbar and 10-1 mbar (compare Figures $5 b$ and $5 c$ and $4 b$ and $4 c$ ). The largest disagreement between modeled and observed ozone is in the band 1000-100 mbar (see Figures $5 a$ and $4 a$ ).

The highest level (10-1 mbar) modeled ozone has a smaller amount than is present in the atmosphere at the winter higher latitudes, but the modeled $\mathrm{O}_{3}$ is quite similar to data at low latitudes and even at high latitudes for other seasons. This good agreement between model and data was unexpected and seemingly contrary to earlier studies, which indicated that the modeled ozone is smaller than observed ozone in this region (first discussed by Butler [1978] and Wofsy [1978]). On closer inspection of the agreement between model and data, we found that the modeled ozone was less than the data between about 7 and 1 mbar and greater than the data between about 7 and 10 mbar. These differences fortuitously cancelled for an apparent good agreement between 10 and 1 mbar for most of the spatial and temporal extent, except at winter high latitudes. At the winter high latitudes the modeled ozone is lower than the data over the entire range from 10 to 1 mbar.

The middle level (100-10 mbar) shows a good deal of similarity between model and observation; the major difference is that the southern hemisphere ozone maximum is off the pole in the data and not in the case A model results.

The largest difference between the data and model is observed in the lowest level (1000-100 mbar). The strong circulation results in a much stronger gradient from the tropics to the poles than is apparent in the data. The modeled ozone in the tropics shows about a factor of 2 less ozone than that seen in the data, whereas the modeled ozone at high latitudes shows more ozone than observed in the data.

The circulation in case A gives too much upward flow in the tropics and too much downward flow at the high latitudes, especially below 100 mbar. A circulation which has strong downward flow for all 12 months of the year in the model at the high latitudes is incorrect. There needs to be upward motion at the high latitudes for several months of the year or decreased downward motion for several months of the year. In the following paragraphs we investigate other circulations and eddy diffusion representations that are different from this "strong circulation" and give different total ozone distributions. A brief description of each dynamical representation, its case designation, and its value of $T_{O_{7}}$ is given in Table 1.

3.1.2. Weak circulation. Guthrie et al. [1984] used a circulation in a trace gas study which is not as strong as that used in case $\mathrm{A}$, described in section 3.1.1. This circulation can be appropriately referred to as the "weak circulation." This circulation is based on Murgatroyd and Singleton [1961] heating rates multiplied by 0.4 for pressure levels from 30 mbar to the top of the model and Dopplick [1974, 1979] heating rates for pressure levels from 30 mbar to the ground. The vertical velocities are weak (i.e., smaller compared to case $A$, the strong circulation) mainly in the lower to middle stratosphere. All other inputs for this model computation (designated case B) were the same as in case A. The total
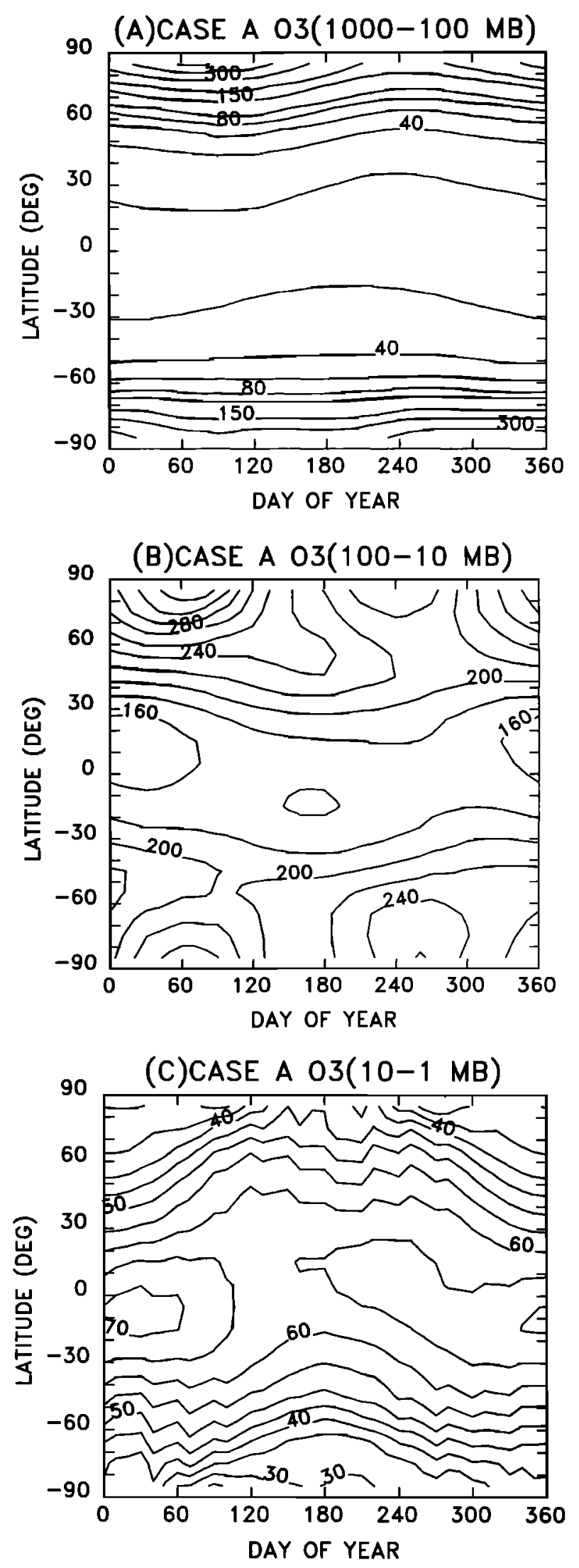

Fig. 5. Total ozone (1n Dobson units) in three layers from model case A (strong circulation): ( $a$ ) surface up to $100 \mathrm{mbar}$ (contours represented are $20,40,60,80,100,150,200,300,400$, and $500 \mathrm{DU})$; (b) 100-10 mbar (contours represented are 160, 180, 200, 220, 240, $260,280,300,320$, and $340 \mathrm{DU}$ ); and (c) 10-1 mbar (contours represented are $25,30,35,40,45,50,55,60,65$, and $70 \mathrm{DU})$. 
TABLE 1. Description of Different Dynamic Cases Investigated With the Two-Dimensional Model, Their Global Average Ozone and Global $\mathrm{O}_{3}$ Change in a Perturbation Scenario With SBUV Data For Comparison

\begin{tabular}{|c|c|c|c|}
\hline Case & Description & $T_{\mathrm{O}_{4}}, \mathrm{DU}$ & $\begin{array}{c}\text { Global } \mathrm{O}_{3} \text { Change } \\
\text { in Perturbation } \\
\text { Experiment, \% }\end{array}$ \\
\hline A & $\begin{array}{l}\text { strong circulation, computed } K_{w} \\
\quad \text { and } K_{v z}\end{array}$ & 290 & -2.1 \\
\hline B & $\begin{array}{l}\text { weak circulation, computed } K_{v v} \\
\text { and } K_{v z}\end{array}$ & 324 & -2.0 \\
\hline $\mathrm{C}$ & $\begin{array}{l}\text { combined circulation, computed } \\
K_{v v} \text { and } K_{v z}\end{array}$ & 320 & -2.4 \\
\hline D & $\begin{array}{l}\text { combined circulation, low } K_{v w} \\
K_{v z}=0\end{array}$ & 317 & -2.4 \\
\hline E & $\begin{array}{l}\text { combined circulation, self- } \\
\text { consistent } K_{v y} \text { and } K_{y z}\end{array}$ & 321 & -2.5 \\
\hline $\mathrm{F}$ & $\begin{array}{l}\text { combined circulation, large } K_{z z} \\
\text { SBUV combined data } \\
\quad(1979-1981)\end{array}$ & $\begin{array}{l}321 \\
298\end{array}$ & -2.4 \\
\hline
\end{tabular}

$T_{\mathrm{O}_{3}}$ indicates global average ozone, in Dobson units.

ozone distribution from case $\mathrm{B}$ is given in Figure 6. The total ozone computed in case $\mathrm{B}$ in the tropics is higher than that observed in SBUV data. In the southern hemisphere the ozone maximum is off the pole in the wintertime, but the maximum is not as large in the southern spring season as in the data. Also, note that in the northern hemisphere the ozone maximum reaches a higher value ( $>500 \mathrm{DU})$ than that indicated in the data. If we compare the lowest layer (surface to 100 mbar) of total ozone from case B with SBUV data (not shown), then there is much better agreement between model and data than that indicated when comparing case $\mathrm{A}$ and data. The $T_{\mathrm{O}_{3}}$ from case B is $324 \mathrm{DU}$, or $\sim 9 \%$ higher than the data.

The streamlines of the winds used in case B (weak circulation) are given in Figure 7 for the month of December. The upward motion which occurs in the summer middle to upper stratosphere and the downward motion in the winter stratosphere are apparent, as in case A (strong circulation), although there are differences in the summer middle to upper stratosphere between cases A and B. Most dramatically

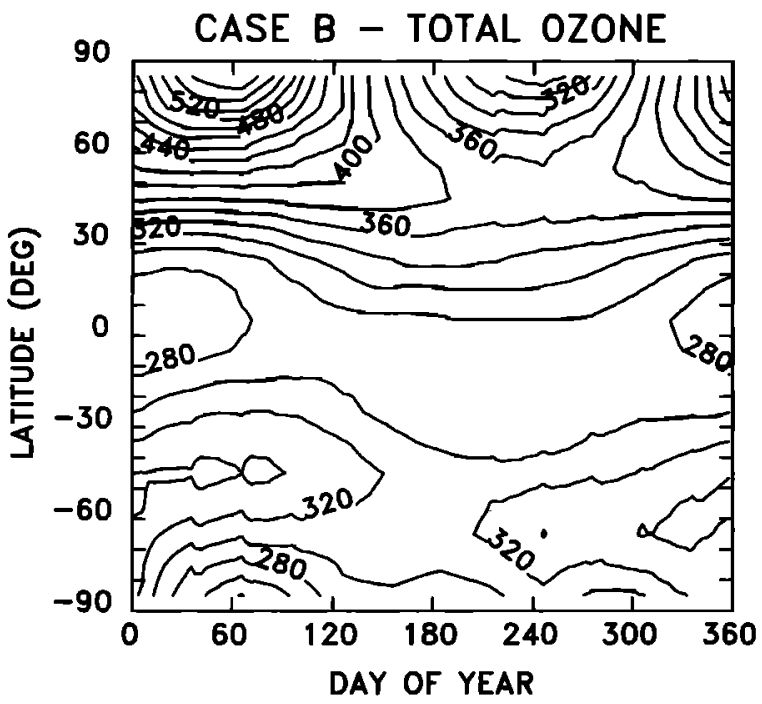

Fig. 6. Total ozone (in Dobson units) from model case B (weak circulation); contours represented are $280,300,320,340,360,380$, $400,420,440,460,480,500,520,540,560$, and $580 \mathrm{DU}$. changed, however, are the circulation patterns at about or just below 100 mbar. Upward motion occurs at high latitudes at both the summer and winter poles, blocking the downward motion at these latitudes above 100 mbar. This blocking effect is present to varying degrees over all 12 months and prevents the huge buildup of $\mathrm{O}_{3}$ at the poles (and resulting large latitudinal ozone gradients) that is present in case A. Also, there is a big difference in the tropical latitudes below 100 mbar. While there is some upward motion, this is combined with other downward motion between $-30^{\circ}$ and $+30^{\circ}$, which prevents a substantial upward movement of $\mathrm{O}_{3}$ to the middle stratosphere where photochemical loss can occur. Ozone spends more time in its conservative region of the atmosphere, which leads to a larger global average amount of ozone $\left(T_{\mathrm{O}_{3}}\right)$ in the model prediction from case B than indicated in case $A$.

3.1.3. Combined circulation. It is apparent that there are problems with the strong circulation discussed in sub-

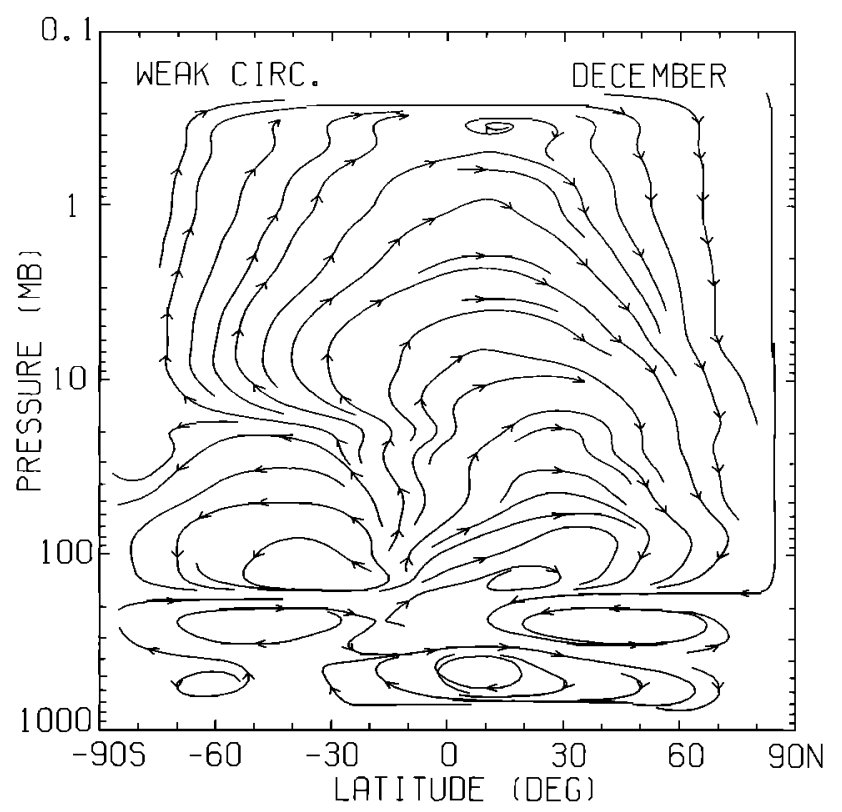

Fig. 7. Streamlines of the "weak circulation", case B, for the month of December. 

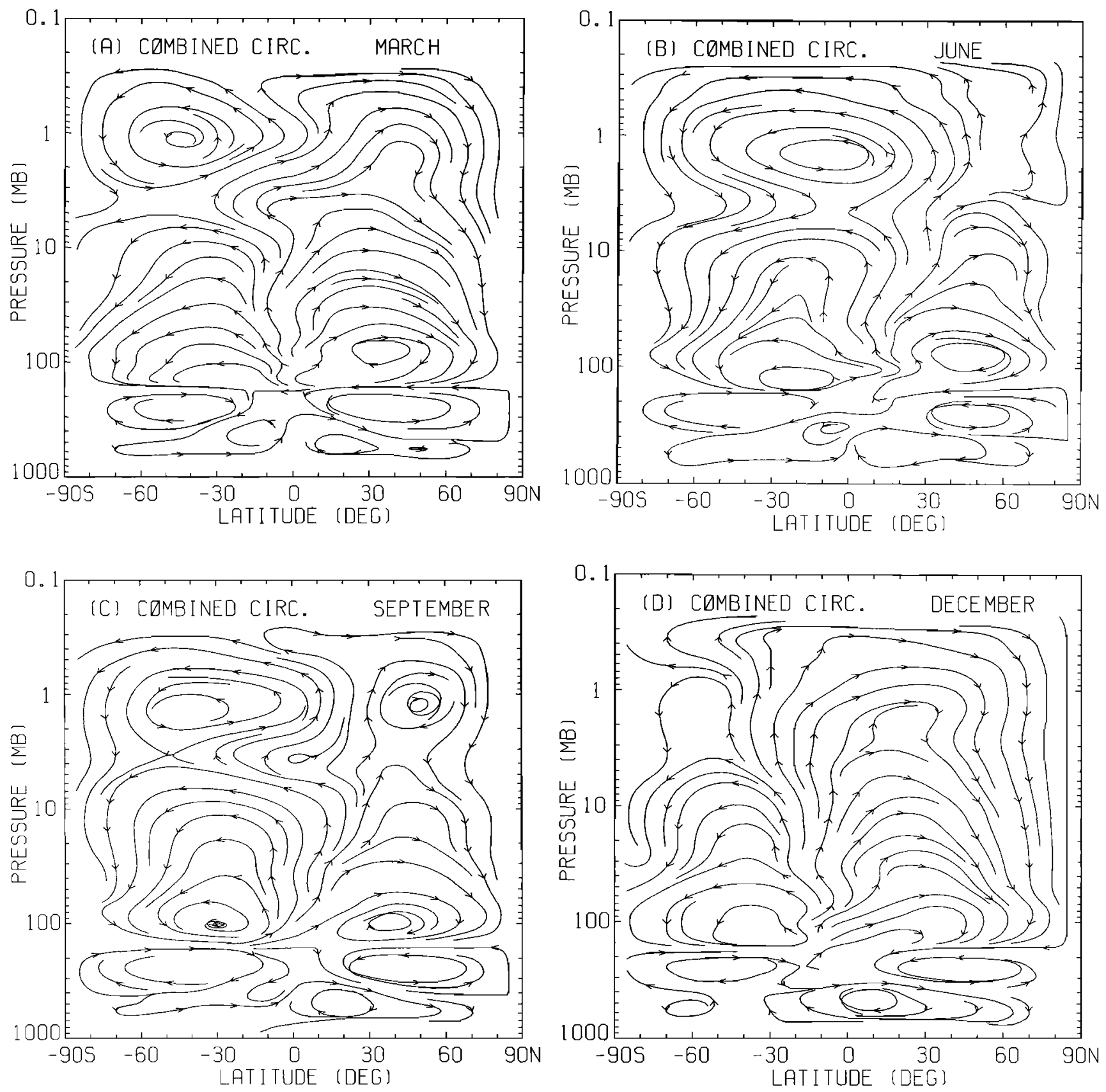

Fig. 8. Streamlines of the "combined circulation", case C, for four separate months: $(a)$ March, (b) June, (c) September, and $(d)$ December.

section 3.1.1., mainly below 100 mbar. The source of the heating rates (which drive the circulation) for the strong circulation is from two papers: (1) Rosenfield et al. [1987] for pressures less than $100 \mathrm{mbar}$ and (2) Wei et al. [1983] for pressures greater than 100 mbar. Indications are that the downward circulation is too strong at the high latitudes for all 12 months of the year in the lower stratosphere and upper troposphere.

We also find problems with the weak circulation predicting an excessive amount of ozone in the northern hemisphere winter high latitudes. There are other difficulties with the weak circulation, especially in predicting the distributions of other trace species, such as $\mathrm{CH}_{4}, \mathrm{~N}_{2} \mathrm{O}$, and $\mathrm{NO}_{v}$ (see the appendix). The weak circulation does not transport these other trace species to the higher altitudes, as is indicated in the data available. For example, not enough $\mathrm{CH}_{4}$ and $\mathrm{N}_{2} \mathrm{O}$ are transported upward in the model, when compared to stratospheric and mesosphere sounder (SAMS) data (see Figure $\mathrm{A} 2 a-\mathrm{A} 2 b)$. The amount of $\mathrm{NO}_{v}$ in the upper stratosphere is, subsequently, predicted to be much lower than indicated in LIMS data [Callis et al., 1985] (see Figures Al and $\mathrm{A} 2 \mathrm{c})$.

Because of these considerations, we decided to combine the "weak circulation" from 100 mbar to the ground with the "strong circulation" from 100 mbar to the top of the model. This "combined circulation," called case C, gives streamlines which are presented in Figure 8 and a total ozone pattern which is presented in Figure 9. There are many similarities between the model computations and the SBUV data. The southern hemisphere maximum is off of the pole, 


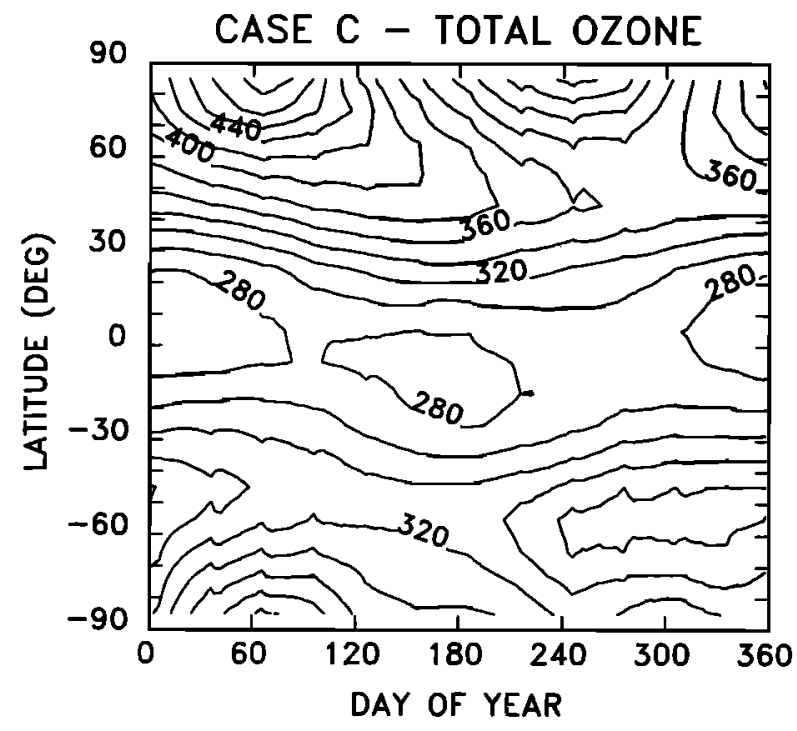

Fig. 9. Total ozone (ın Dobson units) from model case C (combined circulation); contours represented are $280,300,320,340,360$, $380,400,420,440,460,480$, and $500 \mathrm{DU}$.

with a peak over $360 \mathrm{DU}$, and the northern hemisphere maximum values are over $440 \mathrm{DU}$, both fairly similar to the data. However, the $T_{\mathrm{O}}$ is $320 \mathrm{DU}$, higher than the data by 22 DU $(\sim 7 \%)$, and the total ozone peaks earlier at high latitudes than observed in data.

In Figure 10 we present the distribution of ozone for case $\mathrm{C}$ in the three layers: surface to 100 mbar (Figure 10a), 100-10 mbar (Figure 10b), and 10-1 mbar (Figure 10c). There are several similarities with the data, including a fairly good representation of ozone in the first two layers. The modeled ozone between the surface and 100 mbar and between 100 and 10 mbar compares well with the SBUV data. Between 10 and 1 mbar the model and data show many of the similarities discussed previously in section 3.1.1. in the comparison of Figures $4 c$ and $5 c$. In this altitude range, cases $A$ and $C$ have the same circulation, so it is not surprising.

We show a comparison of case $\mathrm{C}$ to the SBUV data in Figure 11, where the ratio is given for the total column $\mathrm{O}_{3}$ and the three layers of total $\mathrm{O}_{3}$, explained earlier. Note that the model (case $\mathrm{C}$ ) predicts an absolute amount of ozone that is $7 \%$ above the SBUV data.

First, observe in Figure $11 a$ that the model has qualitatively too much $\mathrm{O}_{3}$ at middle to lower latitudes, especially in the fall, while the model predicts about the correct amount of $\mathrm{O}_{3}$ at high latitudes in the late winter, spring, and early summer. Between the surface and 100 mbar (Figure $11 b$ ), the model predicts too much $\mathrm{O}_{3}$ in the tropics $\left(-30^{\circ} \mathrm{S}\right.$ to $\left.30^{\circ} \mathrm{N}\right)$, too small an amount of $\mathrm{O}_{3}$ in the northern hemisphere high-latitude winter and spring, and too small an amount of $\mathrm{O}_{3}$ in the southern hemisphere high latitudes.

The $\mathrm{O}_{3}$ in the layer 100-10 mbar (Figure 11c) shows many similarities with the total ozone comparison (Figure 11a); case $\mathrm{C}$ indicates more $\mathrm{O}_{3}$ in the summer and about the same amount of $\mathrm{O}_{3}$ in the winter, when compared to the data. The ozone in the layer 10-1 mbar (Figure $11 d$ ) is quite close to the data, especially in the tropics and at high latitudes in the summer. At winter high latitudes the discrepancies between model and data in this layer indicate that more ozone should be transported from low to high latitudes.
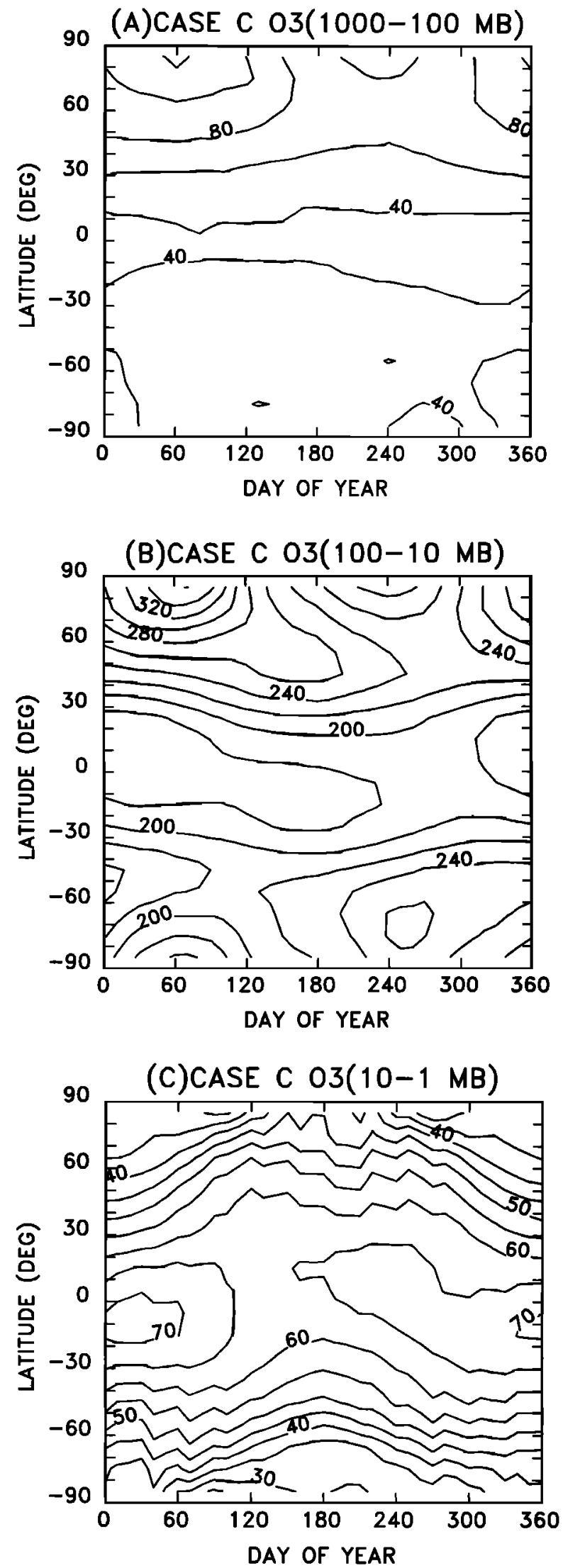

Fig. 10. Total ozone (in Dobson units) in three layers from model case $C$ (combined circulation): $(a)$ surface up to 100 mbar (contours represented are $40,60,80,100$, and $120 \mathrm{DU}$ ), (b) 100-10 mbar (contours represented are 180, 200, 220, 240, 260, 280, 300, 320,340 , and $360 \mathrm{DU}$ ), and (c) 10-1 mbar (contours represented are $25,30.35,40,45,50,55,60,65$, and $70 \mathrm{DU})$. 

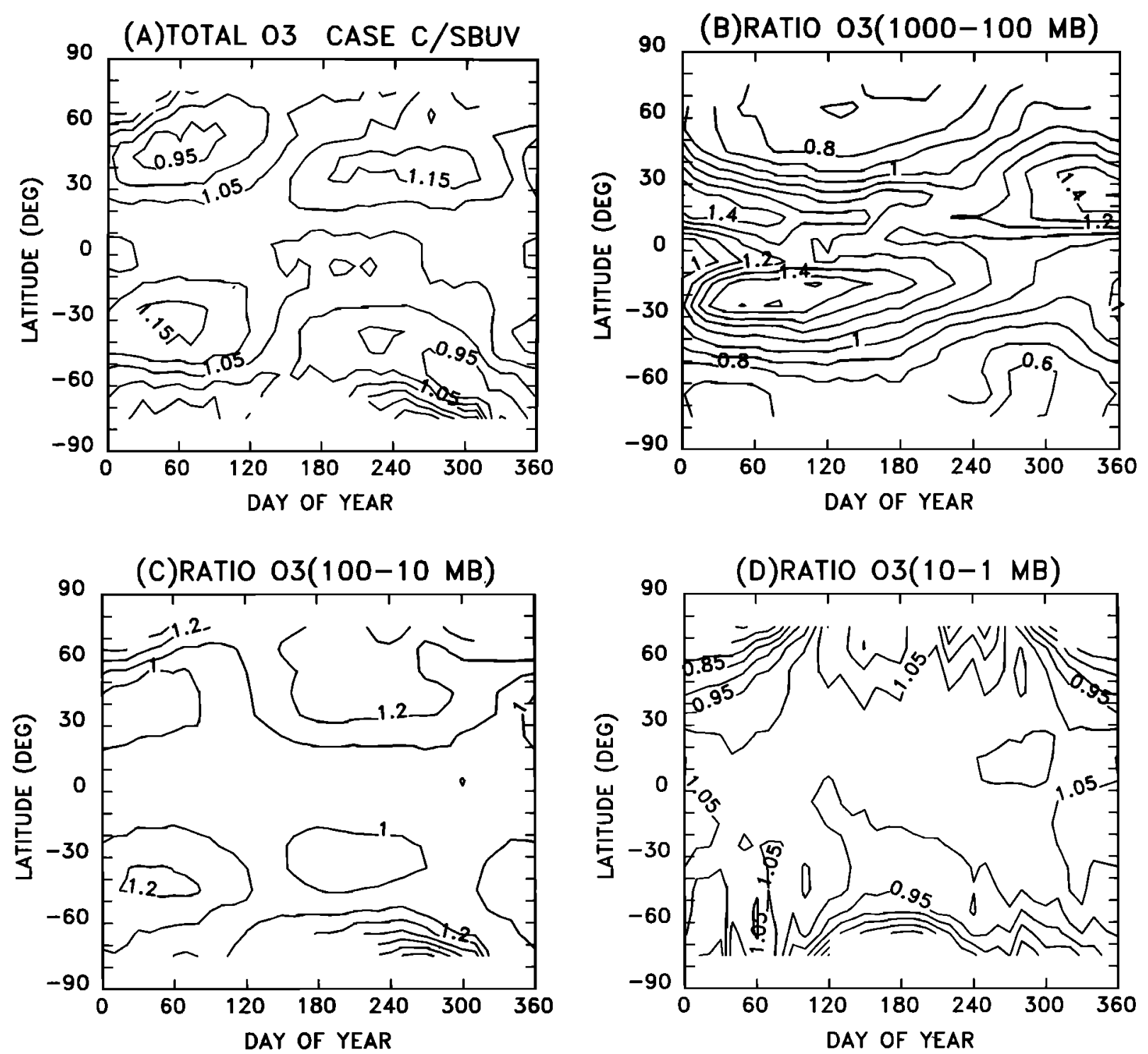

Fig. 11. Ratio of model case C (combined circulatıon) to SBUV ozone data for (a) total ozone (contours represented are $0.95,1.0,1.05,1.1,1.15$, and 1.2), (b) ozone in layer from the surface up to 100 mbar (contours represented are $0.6,0.7,0.8,0.9,1.0,1.1,1.2,1.3,1.4$, and 1.5$)$, (c) ozone in layer from 100 to $10 \mathrm{mbar}(1.0,1.1,1.2$, $1.3,1.4,1.5$, and 1.6$)$, and $(d)$ ozone in layer from 10 to 1 mbar (contours represented are $0.7,0.75,0.8,0.85,0.9,0.95$, $1.0,1.05,1.1$, and 1.15 ).

\subsection{Influence of Eddy Diffusion on}

Total Ozone

The eddy diffusion sensitivity studies discussed below all have the combined circulation (case $C$ ) as their advection field.

3.2.1. Small horizontal eddy diffusion. In this section we investigate the influence of eddy diffusion on the modeled total ozone. We have tried a model run, case $\mathrm{D}$, in which we use $K_{v y}$ set to $2 \times 10^{9} \mathrm{~cm}^{2} \mathrm{~s}^{-1}$ everywhere in the stratosphere (similar to those $K_{v y}$ values recommended from the studies of Kida [1983], Tung [1984], and Ko et al. [1985]) increasing in the troposphere to $1 \times 10^{10} \mathrm{~cm}^{2} \mathrm{~s}^{-1}$ at the ground. We set the $K_{v z}$ equal to 0.0 everywhere. Case D had the "combined circulation" for advection and gave a slightly different total ozone distribution than that indicated in case C. The total ozone distribution is given in Figure 12 from case $\mathrm{D}$. The ozone did not quite reach the large values at the northern hemisphere maximum observed in case $\mathrm{C}$; how- ever, a slightly larger value of total ozone was computed off the pole in the southern hemisphere than that calculated in case $C$ (the area for values greater than $360 \mathrm{DU}$ is larger in case D than case C). This may indicate that the Newman et al. [1988] computed $K_{w, v}$ and $K_{v-}$ used in case C are either too large, or incorrectly distributed temporally and spatially in the southern hemisphere. The $T_{\mathrm{O}_{3}}$ from case $\mathrm{D}$ was computed to be 317 DU.

3.2.2. Self-consistently computed horizontal eddy diffusion. We have also looked at the effects of self-consistent $K_{v v}$ and $K_{v z}$ on the results of our model experiments. Self-consistent $K_{w}$, were computed using the expression [from Jackman et al., 1988]

$$
K_{y v} \simeq \frac{a \bar{u}^{*} \tan \theta}{2}
$$

where $a$ is the radius of the Earth, $\theta$ is the latitude, and $\bar{v}^{*}$ is the meridional velocity. The $K_{w}$ were not allowed to be 


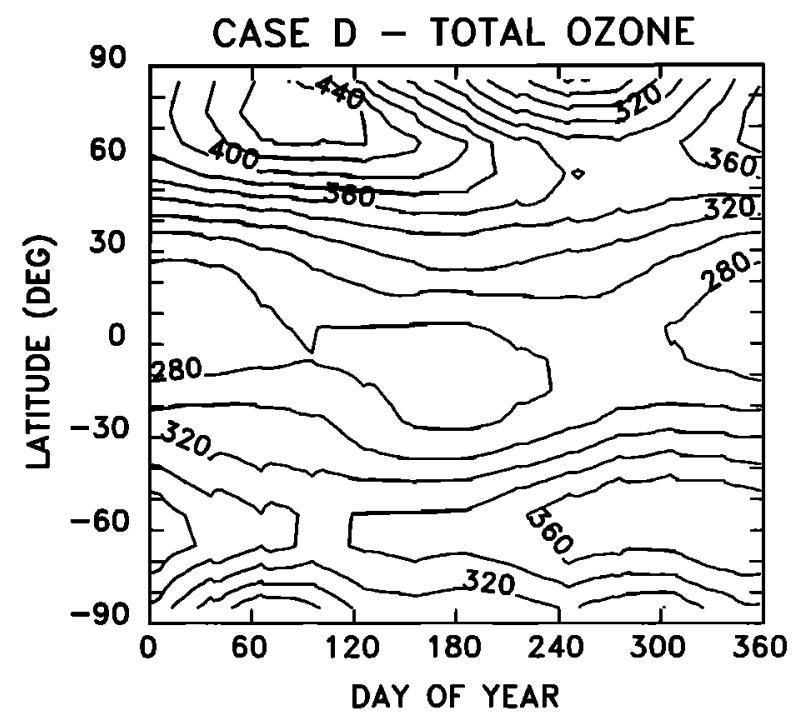

Fig. 12. Total ozone (in Dobson units) from model case D (combined circulation, small horizontal diffusion); contours represented are $260,280,300,320,340,360,380,400,420$, and $440 \mathrm{DU}$.

negative but were set to $2 \times 10^{9} \mathrm{~cm}^{2} \mathrm{~s}^{-1}$ as their smallest values. Negative $K_{y y}$ for a zonal average on time scales of weeks or more are probably unphysical and also lead to numerical problems in model computations (see discussion by Newman et al. [1988], Jackman et al. [1988]). The $K_{v}$ were not allowed to be larger than $5 \times 10^{10} \mathrm{~cm}^{2} \mathrm{~s}^{-1}$ because larger $K_{y v}$ could transport species further than a grid box in one time step and cause model instabilities. This restriction only affected the $K_{v v}$ at latitudes larger than $65^{\circ}$ and altitudes above $1 \mathrm{mbar}$ and thus had virtually no influence on the total ozone results discussed here. The $K_{v:}$ were computed using the self-consistent $K_{v y}$ and the potential temperature gradients, as indicated by Jackman et al. [1988]. The total ozone distribution from this model run (case $\mathrm{E}$ ) is given in Figure 13 and $T_{\mathrm{O}_{3}}$ was computed to be $321 \mathrm{DU}$. The main difference between the total ozone in cases $E$ and $C$ is that the southern hemisphere peak off the pole in July and August has been partially moved poleward in case $\mathrm{E}$ and is also split into two apparent maxima.

3.2.3. Large vertical eddy diffusion. Our final sensitivity study on eddy diffusion and its influence on total ozone involved vertical diffusion, $K_{z z}$. The vertical diffusion is thought to be small in the low to middle stratosphere; however, gravity wave breaking in the upper stratosphere and lower mesosphere should give rise to larger $K_{z z}$ values in that region [Lindzen, 1981]. We use the $K_{z z}$ derived from rocketsonde wind and temperature data by Nastrom et al. [1980] (adapted by Garcia and Solomon [1983] for 2D model use) for this computation, case F. We use our lower values of $K_{z z}$, discussed earlier, for altitudes below $35 \mathrm{~km}$ with $K_{z z}$ being $2 \times 10^{3} \mathrm{~cm}^{2} \mathrm{~s}^{-1}$ in most of the stratosphere. We increase $K_{z z}$ above $35 \mathrm{~km}$ as done by Garcia and Solomon [1983] to $4 \times 10^{5} \mathrm{~cm}^{2} \mathrm{~s}^{-1}$ at the top of our model. This change in atmospheric dynamics is above the ozone peak. The $T_{\mathrm{O}_{3}}$ from case $\mathrm{F}$ is computed to be $321 \mathrm{DU}$, virtually the same as computed in case $\mathrm{C}$. These changes in $K_{z z}$ do affect other minor species, especially above 1 mbar (see appendix, Figure $\mathrm{A} 4 \mathrm{a}-\mathrm{A} 4 \mathrm{c}$ ), but those influences have negligible effects on total ozone and are outside the scope of the discussion here.

\section{Perturbation Studies With Different DYNAMICS}

We have run a combined perturbation study with different circulations and with different $K$. We find that for a perturbation of $\mathrm{Cl}_{v}$ increasing from 2.5 to 8.2 parts per billion by volume (ppbv), $\mathrm{CH}_{4}$ doubling, and $\mathrm{N}_{2} \mathrm{O}$ increasing by $20 \%$, all of the circulations give a very similar global ozone change. For instance, the range in global ozone change is from $-2.0 \%$ for case $B$ to $-2.5 \%$ for case $E$ (see Table 1 ).

The major difference observed in using a different circulation and/or diffusion is the latitudinal dependence of the ozone change. We show the effects of using different advection fields in Figures $14 a$ (strong circulation, case A), $14 b$ (weak circulation), and $14 c$ (combined circulation, case $C$ ). Note that in the case of the strong circulation the peak ozone change is off of the pole in the southern hemisphere and the latitudinal gradient is relatively small. For the case of the weak circulation the peak ozone change is on the pole, but the latitudinal gradient is also very small. In the combined circulation case the peak ozone change is centered on the pole in both hemispheres, with a relatively large latitudinal gradient.

We also show the effects of using different horizontal eddy diffusion in Figures $14 c$ (computed $K_{y y}$ and $K_{y z}$, case C), $14 d$ (small $K_{y v}$, case D), $14 e$ (self-consistent $K_{y y}$ and $K_{y z}$, case E), and $14 f$ (large $K_{z z}$, case $\mathrm{F}$ ). The perturbation distribution is fairly similar in all four of these cases, but the small $K_{v y}$ prediction (Figure $14 d$ ) indicates a maximum ozone change at high latitudes in late spring and early summer, while the computed $K$ prediction (Figure $14 c$ ) indicates a maximum ozone change at high latitudes in early spring. All six perturbation studies predict the smallest ozone changes in the tropical latitudes and larger ozone changes at the middle to high latitudes.

\section{Discussion and Conclusions}

The combined circulation shows the best comparison to SBUV data, even though its $T_{\mathrm{O}_{1}}$ is $7 \%$ above data. Total

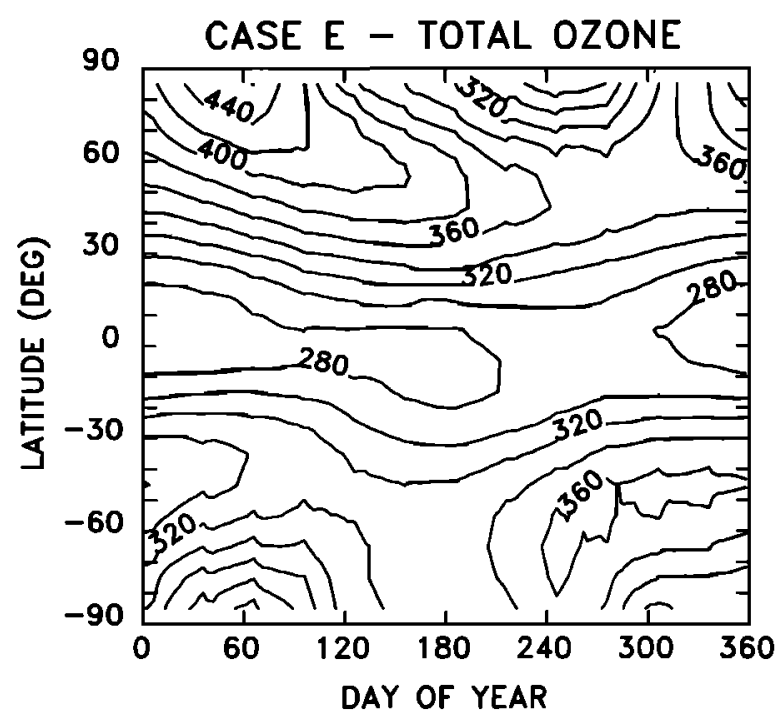

Fig. 13. Total ozone (in Dobson units) from model case E (combined circulation, self-consistent horizontal diffusion); contours represented are $280,300,320,340,360,380,400,420$, and 440 DU. 

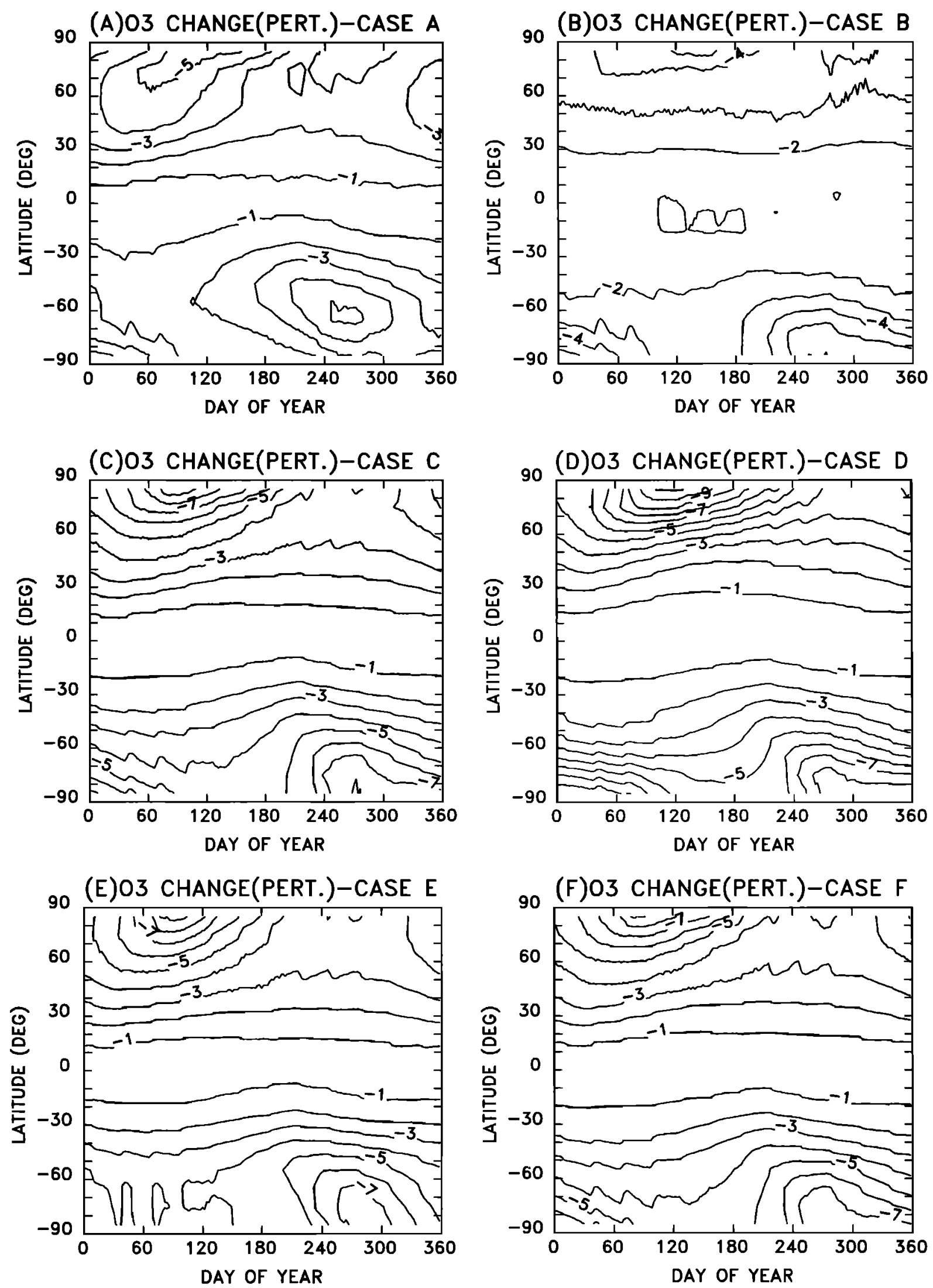

Fig. 14. Percentage total ozone change from combined perturbation (increase $\mathrm{Cl}_{v}$, from 2.5 to 8.2 ppbv, double $\mathrm{CH}_{4}$, and increase $\mathrm{N}_{2} \mathrm{O}$ by $20 \%$ ) for $(a)$ case A (strong circulation, computed horizontal diffusion), $(b)$ case $\mathrm{B}$ (weak circulation, computed horizontal diffusion), $(c)$ case $\mathrm{C}$ (combıned circulation, computed horizontal diffusion), (d) case D (combined circulation, small horizontal diffusion), $(e)$ case $\mathrm{E}$ (combined circulation, self-consistent horizontal diffusion), and $(f)$ case $\mathrm{F}$ (combined circulation, large vertical diffusion). Contours represented for all graphs are -1 , $-2,-3,-4,-5,-6,-7,-8,-9,-10$, and $-11 \%$. 
modeled ozone is less sensitive to the eddy diffusion changes that were investigated and is more sensitive to the different studied circulations. Our model ozone results indicate a large sensitivity to heating rates (which drive the residual circulation), especially those used below 100 mbar. Unfortunately, the most uncertainty in the heating rates occurs below 100 mbar [WMO, 1986].

The atmosphere goes through small year-to-year changes in the ozone distribution that affect the heating rates, which in turn affect the circulation and feed back into the ozone distribution. Other radiatively active gases are undergoing anthropogenic increases, including $\mathrm{CO}_{2}, \mathrm{CH}_{4}, \mathrm{CFCl}_{3}$, and $\mathrm{CF}_{2} \mathrm{Cl}_{2}$. Their increases mean that dynamical changes should be expected in the future (for more discussion on this point see Harwood and Pyle [1980]; Haigh and Pyle [1982]; Haigh [1984]; Solomon et al. [1985]; Eckman et al. [1987]). We do not expect the total ozone to vary dramatically as a result of year-to-year changes in the heating rates; however, some changes in the total $\mathrm{O}_{3}$ distribution from heating rate changes are expected. While perturbation studies indicate ozone decreases of a couple percent, it may be difficult to separate anthropogenic chemical change from anthropogenic or natural dynamical changes in the low and middle latitudes.

It is interesting that the six perturbation ozone change distributions (Figures 14a-14f) are somewhat similar, especially in the low and middle latitudes, in spite of the vast change in dynamics. All studies predict the largest ozone changes at the middle to high latitudes, with smallest changes in the tropical latitudes, similar to most other 2D model results (see, for example, WMO [1986]). The global ozone change in the six studies is also remarkably the same, ranging from 2.0 to $2.5 \%$ ozone depletion. In contrast, the sensitivity of global ozone change to photochemical reaction rates was shown to be substantial [Stolarski and Douglass, 1986] in a one-dimensional (1D) model study.

The results of our several model experiments indicate that the ozone representation of the atmosphere from our 2D model is imperfect. We have used circulations which give $T_{\mathrm{O}_{3}}$ values that bracket the SBUV data. Our results imply that the "correct" 2D residual mean circulation should have a larger vertical velocity in the lower tropical stratosphere than that computed in our combined advection field (case $C$ ). The combined circulation is a product of two different sources of heating rates. We plan on including heating rates computed using the same radiative transfer code from the ground up to the mesosphere in a future study (Joan Rosenfield, private communication, 1988).

Finally, this study relates to our work on $\mathrm{N}_{2} \mathrm{O}$ and the influence of horizontal eddy diffusion [Jackman et al., 1988]. In that paper we concluded that the best model comparison to $\mathrm{N}_{2} \mathrm{O}$ SAMS data came from the use of larger $K_{y y}$ and $K_{y z}$ values (self-consistent calculation, case $\mathrm{E}$ ) in our model. Our modeled total $\mathrm{O}_{3}$ using computed $K$ (case $\mathrm{C}$ ) is qualitatively similar to SBUV data and our modeled total $\mathrm{O}_{3}$ using self-consistent $K$ (case E) is less similar to the SBUV data. Our other results, especially when comparing $\mathrm{O}_{3}$ between 10 and $1 \mathrm{mbar}$, indicate that more meridional mixing is needed to transport $\mathrm{O}_{3}$ to the poles in the wintertime. This means either (1) the computed $K$ are correct qualitatively and occur at the right time of the year but are not large enough, or (2) the combined circulation is too strong and needs to be reduced in the middle stratosphere (the computed $K$ would then be more consistent with this reduced circulation). At the present time, we can only conclude that our "best" horizontal eddy diffusion and mean residual circulation (case $\mathrm{C}$, combined circulation) are not consistent.

\section{ApPendix: Variation of Other SPEcies With Dynamical InPUTS}

Other species, besides ozone, vary with the different dynamical inputs. We compare our model results to both SAMS and LIMS data by showing $\mathrm{CH}_{4}, \mathrm{~N}_{2} \mathrm{O}$, and $\mathrm{NO}_{y}(\mathrm{~N}$, $\mathrm{NO}, \mathrm{NO}_{2}, \mathrm{NO}_{3}, \mathrm{HNO}_{3}, \mathrm{HO}_{2} \mathrm{NO}_{2}, \mathrm{~N}_{2} \mathrm{O}_{5}$, and $\mathrm{ClONO}_{2}$ ) for March from the three extreme cases $\mathrm{B}, \mathrm{C}$, and $\mathrm{F}$.

LIMS nighttime $\mathrm{NO}_{2}+\mathrm{HNO}_{3}$ is given in Figure $\mathrm{Al}$ and will be compared to our modeled $\mathrm{NO}_{y}$ distributions in Figures A2c, A3c, and A4c. We use the profile archived data for our LIMS values and find that the peak levels are slightly less than those given by Callis et al. [1985], who used a data set for $\mathrm{NO}_{2}$ that included a radiance average to derive the $\mathrm{NO}_{2}$ distribution. Between 35 and $50 \mathrm{~km}$ the nighttime $\mathrm{NO}_{2}$ $+\mathrm{HNO}_{3}$ represents more than $75 \%$ of the $\mathrm{NO}_{y}$ in the atmosphere (see Callis et al. [1985] and Jackman et al. [1987]). The SAMS data is presented in Figures A2a-2b, $A 3 a-3 b$, and $A 4 a-4 b$, with a dashed line for easier comparison to the data.

The weak circulation (case $\mathrm{B}$ ) gives $\mathrm{CH}_{4}$ and $\mathrm{N}_{2} \mathrm{O}$ distributions that are far removed from SAMS data (see Figures A2a-2b). The trace gases are not being transported above 10 mbar in any manner representing reality, even considering the large uncertainties in the SAMS data [Jones and Pyle, 1984]. The $\mathrm{NO}_{y}$ from the weak circulation shows a peak distribution of only about 18 ppbv. The LIMS $\mathrm{NO}_{2}+\mathrm{HNO}_{3}$ distribution translates into a peak of $25.5 \pm 4.5 \mathrm{ppbv}$ [Callis et al., 1985]. This indicates that the modeled $\mathrm{NO}_{y}$ is lower than the data by $15-40 \%$ (using $21-30$ ppbv as the bounds of the odd nitrogen LIMS data) at the peak of its distribution. Calculated $\mathrm{NO}_{y}$ is much lower than LIMS $\mathrm{NO}_{2}+\mathrm{HNO}_{3}$ in the lower stratosphere, even though the model contains a lightning source of $\mathrm{NO}_{y}$ (the $\mathrm{H} 2$ source of $\mathrm{Ko}$ et al. [1986]).

The combined circulation (case $\mathrm{C}$ ) gives $\mathrm{CH}_{4}$ and $\mathrm{N}_{2} \mathrm{O}$ distributions that are much closer to SAMS data (Figures

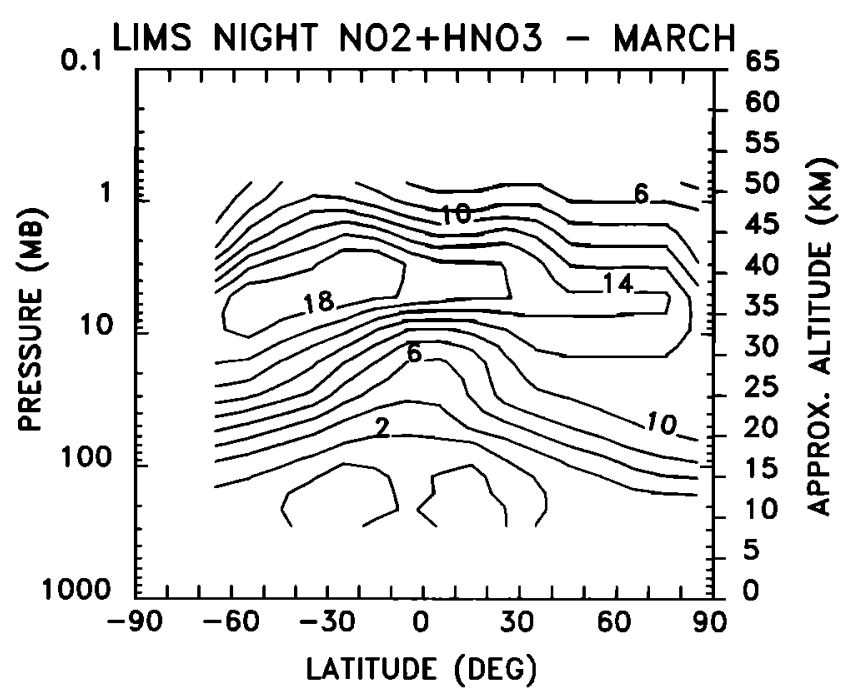

Fig. A1. LIMS nighttime $\mathrm{NO}_{2}+\mathrm{HNO}_{3}$ for March, using the profile archived data set; contours represented are 1, 2, 4, 6, 8, 10, $12,14,16$, and 18 ppbv. 

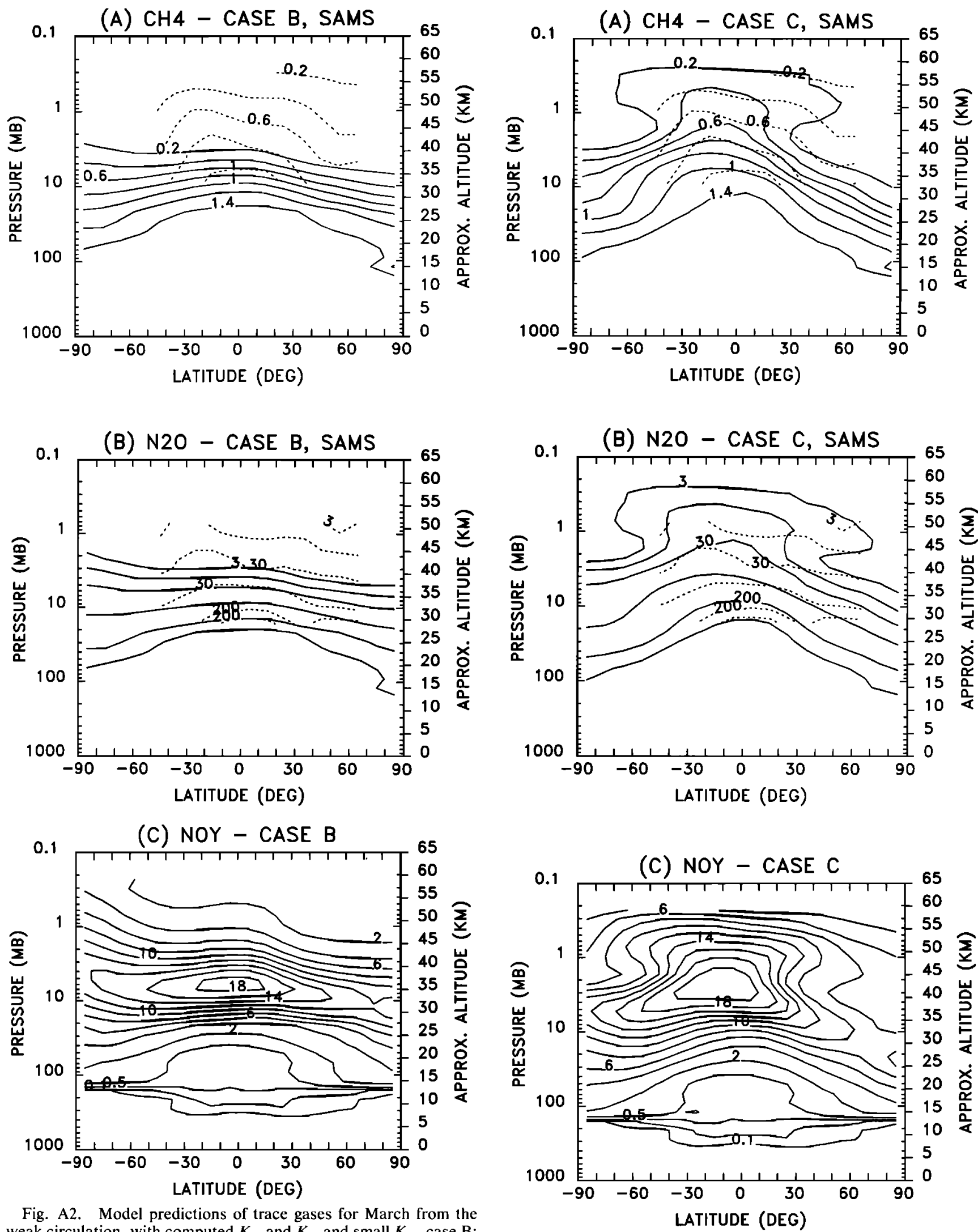

Fig. A2. Model predictions of trace gases for March from the weak circulation, with computed $K_{v v}$ and $K_{v z}$ and small $K_{z z}$, case B: (a) for $\mathrm{CH}_{4}$ the model predictions are represented as the solid line and the SAMS data as the dashed line (contours represented are 0.2 , $0.4,0.6,0.8,1.0,1.2$, and $1.4 \mathrm{ppmv}$ ); (b) for $\mathrm{N}_{2} \mathrm{O}$ the model predictions are represented as the solid line and the SAMS data as the dashed line (contours represented are 3,10,30, 100,200, and 250 ppbv); and $(c)$ for model-predicted $\mathrm{NO}_{v}$ (contours represented are $0.1,0.2,0.5,1,2,4,6,8,10,12,14,16,18,20 \mathrm{ppbv}$ ).

Fig. A3. Model predictions of trace gases for March from the combined circulation, with computed $K_{v y}$ and $K_{v z}$ and small $K_{z z}$, case $\mathrm{C}$ : $(a)$ for $\mathrm{CH}_{4}$ the model predictions are represented as the solid line and the SAMS data as the dashed line; $(b)$ for $\mathrm{N}_{2} \mathrm{O}$ the model predictions are represented as the solid line and the SAMS data as the dashed line; and $(c)$ for model-predicted NO, Contour levels are as given in Figure A2. 

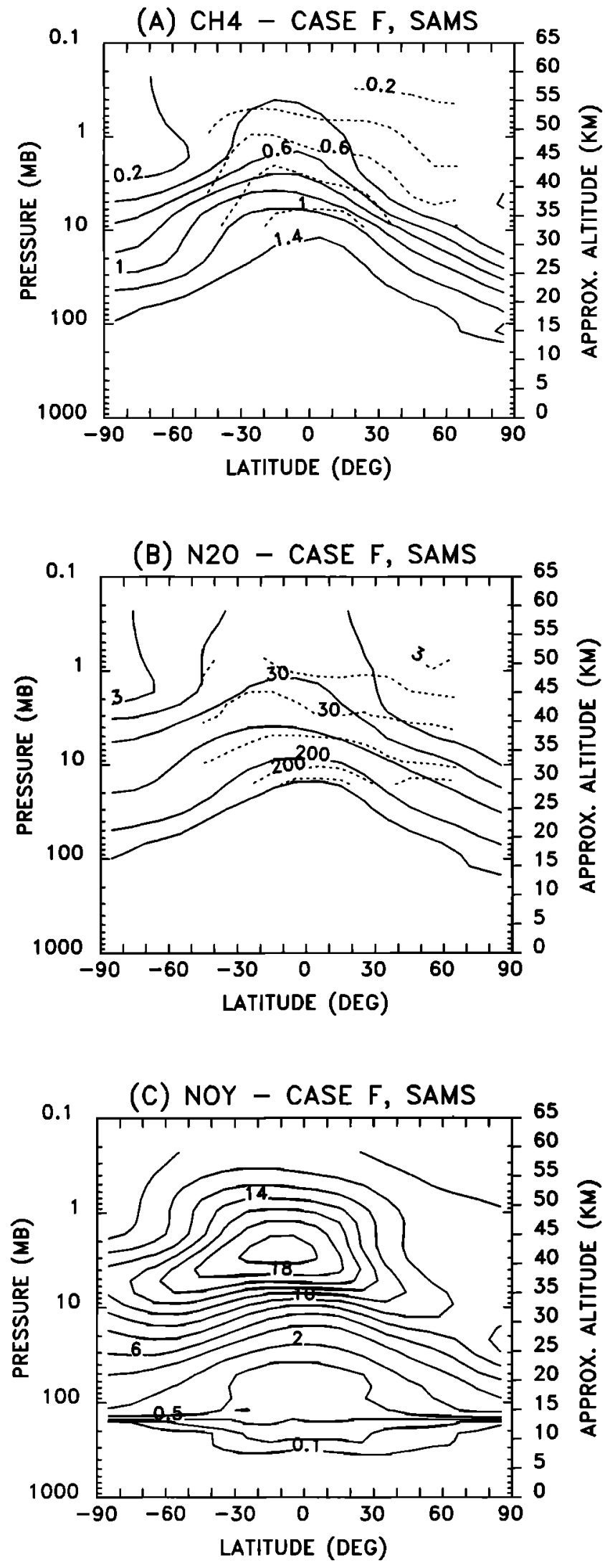

Fig. A4. Model predictions of trace gases for March from the combined circulation, with computed $K_{y y}$ and $K_{y z}$ and large $K_{z z}$ case F: $(a)$ for $\mathrm{CH}_{4}$ the model predictions are represented as the solid line and the SAMS data as the dashed line; $(b)$ for $\mathrm{N}_{2} \mathrm{O}$ the model predictions are represented as the solid line and the SAMS data as the dashed line; and $(c)$ for model-predicted $\mathrm{NO}_{r}$. Contour levels are as given in Figure A2.
$\mathrm{A} 3 a-\mathrm{A} 3 b)$. Although the agreement is not perfect, similar amounts of $\mathrm{CH}_{4}$ and $\mathrm{N}_{2} \mathrm{O}$ are predicted by the model and observed in the data, especially in the tropics. At higher latitudes the data show larger values of both $\mathrm{CH}_{4}$ and $\mathrm{N}_{2} \mathrm{O}$, indicating that either (1) more horizontal mixing should be included in the calculation or (2) the vertical velocities (both upward and downward) should be decreased in magnitude. These conclusions are similar to those of Jackman et al. [1988]. The $\mathrm{NO}_{y}$ from the combined circulation shows a peak distribution of near 21 ppbv. The modeled odd nitrogen is therefore much closer to the LIMS data and is lower than the data only by 0-30\% (again, using 21-30 ppbv as the bounds of the odd nitrogen LIMS data). As in case $\mathrm{B}$, the $\mathrm{NO}_{y}$ is much less than LIMS $\mathrm{NO}_{2}+\mathrm{HNO}_{3}$ in the lower stratosphere.

The combined circulation with the high $K_{z z}$ (case F) gives $\mathrm{CH}_{4}$ and $\mathrm{N}_{2} \mathrm{O}$ distributions that are similar to SAMS data up to about 1 mbar. Above 1 mbar, however, the model predicts too large an amount of the trace gases at many altitudes in the tropical latitudes (see Figures $\mathrm{A} 4 a-\mathrm{A} 4 b$ ). The $\mathrm{NO}_{y}$ from case $\mathrm{F}$ shows a peak distribution over $20 \mathrm{ppbv}$, similar to case C. Near 1 mbar $(49 \mathrm{~km})$ the modeled $\mathrm{NO}_{y}$ shows values up to $16 \mathrm{ppbv}$, much larger than indicated in Figure A1 (maximum of about $10 \mathrm{ppbv}$ ) when it is assumed that the LIMS nighttime $\mathrm{NO}_{2}+\mathrm{HNO}_{3}$ represents over $95 \%$ of $\mathrm{NO}_{y}$ at that altitude (see Callis et al. [1985]; also, our own model calculations). The lower stratosphere $\mathrm{NO}_{y}$ disagreement between model and LIMS data persists in case F as well.

Acknowledgments. We thank Richard McPeters (NASA Goddard Space Flight Center (GSFC) and Joan Stokes (Science Applications Research) for providing a 3-year average SBUV ozone data set. We appreciated the useful discussions with Joan Rosenfield (Sigma Data) and the helpful comments from Jack Kaye and Richard Rood (NASA GSFC) on a preliminary version of this manuscript. We also thank the reviewers for useful comments.

\section{REFERENCES}

Bass, A. M., and R. J. Paur, The ultraviolet cross-sections of ozone, I, The measurements, Atmospheric Ozone, Proceedings of the Quadrennial Ozone Symposium, Halkidiki, Greece, edited by C. S. Zerefos and A. Ghazi, pp. 606-610, D. Reidel, Hingham, Mass., 1985.

Butler, D. M., The uncertainty in ozone calculations by a stratospheric photochemistry model, Geophys. Res. Lett., 5, 769-772, 1978 .

Callis, L. B., M. Natarajan, and J. M. Russell, III, Estimates of the stratospheric distribution of odd nitrogen from LIMS data, Geophys. Res. Lett., 12, 259-262, 1985.

Climatic Impact Assessment Program, Report of findings: The effects of stratospheric pollution by aircraft, edited by A. J. Grobecker, S. C. Coroniti, and R. H. Cannon, Jr., Rep. DOTTST-75-50, 551 pp., Dep. of Transp., Washington, D. C., 1974.

DeMore, W. B., M. J. Molina, S. P. Sander, D. M. Golden, R. F. Hampson, M. J. Kurylo, C. J. Howard, and A. R. Ravishankara, Chemical kinetıcs and photochemical data for use in stratospheric modeling, JPL Publ., 87-4I, 1987.

Dopplick, T. G., The heat budget, in The General Circulation of the Tropical Atmosphere and Interactions With Extratropical Latitudes, vol. 2, edited by R. E. Newell, J. W. Kidson, D. G. Vincent, and C. J. Boer, pp. 27-94, The MIT Press, Cambridge, Mass., 1974.

Dopplick, T. G., Radiative heatıng of the global atmosphere: Corrigendum, J. Atmos. Sci., 36, 1812-1817, 1979.

Douglass, A. R., C. H. Jackman, and R. S. Stolarski, Comparison of model results transporting the odd nitrogen family with separate results transporting odd nitrogen species, J. Geophys. Res., this issue.

Eckman, R. S., J. D. Haigh, and J. A. Pyle, An important uncer- 
tainty in coupled chlorine-carbon dioxide studies of atmospheric ozone modifications, Nature, 329, 616-619, 1987.

Garcia, R. R., and S. Solomon, A numerical model of the zonally averaged dynamical and chemical structure of the middle atmosphere, J. Geophys. Res., 88, 1379-1400, 1983.

Guthrie, P. D., C. H. Jackman, J. R. Herman, and C. J. McQuillan, A diabatic circulation experiment in a two-dımensional photochemical model, $J$ Geophys. Res., 89, 9589-9602, 1984.

Haigh, J. D., Radiative heating in the lower stratosphere and the distribution of ozone in a two-dimensional model, $Q . J . R$. Meteorol. Soc., 110, 167-185, 1984.

Haigh, J. D., and J. A. Pyle, Ozone perturbation experiments in a two-dimensional circulation model, Q.J.R. Meteorol. Soc., 108, 551-574, 1982.

Harwood, R. S., and J. A. Pyle, The dynamical behaviour of a two-dimensional model of the stratosphere, $O . J . R$. Meteorol. Soc., 106, 395-420, 1980.

Jackman, C. H., R. S. Stolarski, and J. A. Kaye, Two-dimensional monthly average ozone balance from Limb Infrared Monitor of the Stratosphere and Stratospheric and Mesospheric Sounder data, J. Geophys. Res., 91, 1103-1116. 1986.

Jackman, C. H., P. D. Guthrie, and J. A. Kaye, An intercomparison of nitrogen-containing species in Nimbus 7 LIMS and SAMS data, J. Geophys. Res., 92, 995-1008, 1987.

Jackman, C. H., P. A. Newman, P. D. Guthrie, and M. R. Schoeberl, Effect of computed horizontal diffusion coefficients on two-dimensional $\mathrm{N}_{2} \mathrm{O}$ model distributions, J. Geophys. Res., 93. 5213-5219, 1988.

Jones, R. L., and J. A. Pyle, Observations of $\mathrm{CH}_{4}$ and $\mathrm{N}_{2} \mathrm{O}$ by the Nimbus 7 SAMS: A comparison with in situ data and twodimensional numerical model calculations, J. Geophys. Res., 89. 5263-5279, 1984.

Kıda, H., General circulation of air parcels and transport in the stratosphere and troposphere derived from CCM. 1, Mean mass flow in the lower stratosphere, J. Meteorol. Soc. Jpn., 6I, 171-186, 1983.

Ko, M. K. W., K. K. Tung, D. K. Weisenstein, and N. D. Sze. A zonal mean model of stratospheric tracer transport in isentropic coordınates: numerical simulation for nitrous oxıde and nitric acid, J. Geophys. Res., 90, 2313-2329, 1985.

Ko, M. K. W., M. B. McElroy, D. K. Weisenstein, and N. D. Sze, Lightnıng: A possible source of stratospheric odd nitrogen, $J$. Geophys. Res., 91, 5395-5404, 1986.

Lindzen, R. S., Turbulence and stress owing to gravity and tidal breakdown, J. Geophys. Res., 86, 9707-9714, 1981.

McPeters, R. D., D. F. Heath, and P. K. Bhartia, Average ozone profiles for 1979 from the Nimbus 7 SBUV instrument, J. Geophys. Res., 89, 5199-5214, 1984.

Murgatroyd, R. J., and F. Singletow, Possible meridional circulation
In the stratosphere and mesosphere, $Q . J . R$. Meteorol. Soc., 87, 125-135, 1961

Nastrom, G. D., A. D. Belmont, and D. E. Brown, Eddy diffusion coefficients and the variance of the atmosphere $30-60 \mathrm{~km}$. Pure Appl. Geophys., 1/8, 1015-1032, 1980.

National Aeronautics and Space Administration. The stratosphere: Present and future, edited by R. D. Hudson and E. I. Reed, NASA Ref. Publ., 1049, 432 pp., 1979.

Newman, P. A., M. R. Schoeberl, R. A. Plumb, and J. E. Rosenfield, Mixing rates calculated from potentsal vorticity, J. Geophys. Res. 93, 522I-5240, 1988.

Paur, R. J., and A. M. Bass, The ultraviolet cross-sections of ozone: II, Results and temperature dependence, Atmospheric Ozone, Proceedings of the Quadrennial Ozone Symposium, Halkidiks, Greece, edited by C. S. Zerefos and A. Ghazi, pp. 611-616, D. Reıdel, Hıngham, Mass., 1985.

Rood, R. B., and M. R. Schoeberl, Ozone transport by diabatic and planetary wave circulations on a $\beta$ plane, J. Geophys. Res., 88 , 8491-8504, 1983.

Rosenfield, J. E., M. R. Schoeberl, and M. A. Geller, A computation of the stratospheric diabatic residual circulation using an accurate radiatıve transfer model, J. Atmos. Sci., 44, 859-876, 1987.

Solomon, S., R. R. Garcia, and F. Stordal, Transport processes and ozone perturbations, J. Geophys. Res., 90, 12,981-12,989, 1985.

Stolarski, R. S., and A. R. Douglass, Sensitivity of an atmospheric photochemistry model to chlorine perturbations including consideration of uncertainty propagation, J. Geophys. Res.. 91, 78537864,1986

Tung, K. K., Modeling of tracer transport in the middle atmosphere, Dynamics of the Middle Atmosphere, edited by J. R. Holton and T. Matsuno, pp. 412-444, Terra Scientıfic, Tokyo, Japan, 1984.

Wei, M.-Y., D. R. Johnson, and R. D. Townsend, Seasonal distributions of diabatic heating during the first GARP global experiment, Tellus, 35A, 241-255, 1983.

Wofsy, S. C., Temporal and latitudinal variations of stratospheric trace gases: A critical comparison between theory and experiment, J. Geophys. Res., 83, 364-378, 1978.

World Meteorological Organization. The stratosphere 1981: Theory and measurements, Rep. I/, Global Ozone Res, and Monit. ProJ.. Geneva, 1982.

World Meteorological Organization, Atmospheric ozone 1985, Re $p$. 16. Global Ozone Res. and Monit. Proj., Geneva, 1986.

A. R. Douglass, P. D. Guthrie, C. H. Jackman, and R. S. Stolarski, Atmospheric Chemistry and Dynamics Branch, Code 616 , NASA Goddard Space Flight Center, Greenbelt, MD 20771.

(Received August 2, 1988; revised March 2, 1989; accepted March 2, 1989.) 